\title{
Putting things in new places: Linguistic experience modulates the predictive power of placement verb semantics
}

\author{
Geertje van Bergen*, Monique Flecken \\ Max Planck Institute for Psycholinguistics, Wundtlaan 1, 6525 XD Nijmegen, The Netherlands
}

\section{A R T I C L E I N F O}

\section{Article history:}

Received 16 August 2015

revision received 12 May 2016

\section{Keywords:}

Predictive processing

Sentence comprehension

Language experience

L2 processing

Cross-linguistic diversity

Visual world eye tracking

\begin{abstract}
A B S T R A C T
A central question regarding predictive language processing concerns the extent to which linguistic experience modulates the process. We approached this question by investigating sentence processing in advanced second language (L2) users with different native language (L1) backgrounds. Using a visual world eye tracking paradigm, we investigated to what extent L1 and L2 participants showed anticipatory eye movements to objects while listening to Dutch placement event descriptions. L2 groups differed in the degree of similarity between Dutch and their L1 with respect to placement verb semantics: German, like Dutch, specifies object position in placement verbs (put.STAND vs. put.LIE), whereas English and French typically leave position underspecified (put). Results showed that German L2 listeners, like native Dutch listeners, anticipate objects that match the verbally encoded position immediately upon encountering the verb. French/English L2 participants, however, did not show any prediction effects, despite proper understanding of Dutch placement verbs. Our findings suggest that prior experience with a specific semantic contrast in one's L1 facilitates prediction in L2, and hence adds to the evidence that linguistic experience modulates predictive sentence processing.
\end{abstract}

(c) 2016 Elsevier Inc. All rights reserved.

\section{Introduction}

There is now broad agreement that incremental language understanding does not entail passive integration. Language comprehenders can use linguistic and nonlinguistic cues to actively generate predictions about upcoming words and structures (for reviews, see e.g., Federmeier, 2007; Huettig, 2015; Kamide, 2008; Kuperberg \& Jaeger, 2016; Kutas, Delong, \& Smith, 2011; Pickering \& Garrod, 2013; van Petten \& Luka, 2012). Predictions can be reflected in, for instance, anticipatory eye movements to elements in a visual display while listening to speech (visual world eye-tracking, e.g., Altmann \& Kamide, 1999; Tanenhaus, Spivey-Knowlton, Eberhard, \&

\footnotetext{
* Corresponding author.

E-mail addresses: geertje.vanbergen@mpi.nl (G. van Bergen), monique. flecken@mpi.nl (M. Flecken).
}

Sedivy, 1995; review in Huettig, Meyer, \& Rommers, 2011), or in modulations of event-related potentials on sentence elements preceding a disambiguating content word during reading (EEG methodology, e.g., DeLong, Urbach, \& Kutas, 2005; Federmeier \& Kutas, 1999; van Berkum, Brown, Zwitserlood, Kooijman, \& Hagoort, 2005). The cues used to generate such predictions range from linguistic (e.g., Hare, Jones, Thomson, Kelly, \& McRae, 2009; Kaiser \& Trueswell, 2004) and visual (e.g., Knoeferle, Crocker, Scheepers, \& Pickering, 2005) context to morphosyntactic features (such as case and gender marking; e.g., Kamide, Altmann, \& Haywood, 2003), prosody (e.g., Kurumada, Brown, Bibyk, Pontillo, \& Tanenhaus, 2014), and semantic information encoded in verbs (e.g., Altmann \& Kamide, 1999). As for the contents of the prediction, evidence points to a range of highly specific to slightly more abstract linguistic information, from specific lexical forms (e.g., Dahan \& Tanenhaus, 2000; DeLong et al., 
2005; van Berkum et al., 2005) to thematic role information (e.g., Kamide, Scheepers, \& Altmann, 2003), and more general semantic properties of objects (such as edibility; Altmann \& Kamide, 1999). There is also evidence that visual properties of an object are anticipated (e.g., shape; Rommers, Meyer, Praamstra, \& Huettig, 2013). Generating predictions is considered crucial to the language processing system, leading to faster and more efficient mental operations (e.g., Farmer, Brown, \& Tanenhaus, 2013; Fine, Jaeger, Farmer, \& Qian, 2013; Hale, 2003; Levy, 2008). The language comprehension system is assumed to constantly keep track of the (in)coherence between anticipated and actual outcomes (e.g., Clark, 2013; MacDonald, 2013; van Berkum, 2010). On the basis of the resulting prediction error, expectations about future outcomes are adapted accordingly, hence minimizing the overall prediction error and maximizing communicative efficiency; this is considered the basic principle underlying (implicit) language learning (e.g., Chang, Dell, \& Bock, 2006; Jaeger \& Snider, 2013).

Under the assumption that predictions are based on previous linguistic experience (cf. Chang et al., 2006; Jaeger \& Snider, 2013; MacDonald, 2013; Wells, Christiansen, Race, Acheson, \& MacDonald, 2009), differences in linguistic experience should affect predictive language processing. There is evidence that this is indeed the case: for instance, recent studies show that individual differences in written sentence processing, as measured by eye movements during reading, are best explained in terms of linguistic experience (Farmer, Fine, \& Jaeger, 2011; Kuperman \& van Dyke, 2011; each study using a different proxy for linguistic experience). Studies on literacy and dyslexia report a mediating role of language experience in spoken sentence processing. For instance, Mishra, Singh, Pandey, and Huettig (2012) compared Indian high and low literates' anticipatory eye movements to objects in a visual display while listening to constraining contexts; they found that people with higher reading skills anticipated target objects in the display, while people with lower reading skills only directed their eye gaze to target objects after encountering the critical word. Mani and Huettig (2014) found a similar correlation between reading skills and anticipatory eye gaze for children who are in the process of learning to read (see also Mani \& Huettig, 2012). In Huettig and Brouwer (2015), dyslexic adults (people with reduced reading skills) participated in an eye-tracking experiment in which Dutch gender-marked articles served as predictive cues for the upcoming object (the article agreed in gender with only one of the objects in a display). Compared to non-dyslexic controls, dyslexics showed a delayed anticipation effect in their eye movements, indicating reduced ability to generate predictions about specific lexical forms. These findings together suggest that individual differences in linguistic experience account for variation in the ability to generate predictions during language processing.

A different way of investigating the role of linguistic experience in predictive language processing is by studying second language (L2) learners' predictive ability in their L2. The rationale here is that native and non-native/ L2 speakers differ in their experience with the concepts and forms encoded in the second language, with native speakers being the 'experts' in processing the respective language: Speaker status (native (L1)/L2) is thus taken as a proxy for linguistic experience. The study of L2 users is a way of overcoming some of the difficulties associated with comparing high and low literates, for instance differences in formal education (cf. Mishra et al., 2012). Crucially, L2 research allows for cross-linguistic comparisons using identical linguistic materials, hence facilitating a direct comparison between populations. By controlling for the degree of similarity between the target language and the L2 users' native language in certain linguistic domains, we are able to look at linguistic experience in a more specific way. Participants with a native language background that overlaps with the target language on a specific predictive cue would have more experience in using this cue to generate predictions, compared to participants with a native language that differs from the target language with respect to that predictive cue.

\section{Prediction in L2 sentence processing}

The study of prediction in L2 users and bilinguals is emerging. Researchers have addressed to what extent L2 users and bilinguals predict specific lexical forms, as evidenced through event-related potential modulations on articles preceding nouns (Foucart, Martin, Moreno, \& Costa, 2014; Martin et al., 2013), as well as their ability to use specific linguistic cues for the generation of anticipatory eye movements, such as grammatical gender, case marking, and semantic information encoded in verbs (Dussias, Valdes Kroff, Guzzardo Tamargo, \& Gerfen, 2013; Hopp, 2013, 2015). Generally, studies targeting predictions based on semantic cues show that this process is effortless for L2 users, and that there are no critical differences between native and non-native speakers (e.g., Hopp, 2015; Trenkic, Mirkovic, \& Altmann, 2014). However, multiple researchers have shown that L2 users do have trouble using (morpho)syntactic cues for prediction in L2 processing. For example, Martin et al. (2013) performed an EEG study of predictive processing in English monolinguals and Spanish-English bilinguals. Participants read constraining sentences in English in which the researchers systematically manipulated the final noun (expected vs. unexpected) and the preceding article (a/an), e.g., the day was breezy so the boy went outside to fly a kite/an airplane. If the form of the preceding article did not match with the expected noun, the researchers found an N400 modulation in monolinguals, but not in bilinguals. On the basis of this finding the authors conclude that bilinguals do not generate predictions about articles to the same extent as monolinguals do. Hopp (2013) used a visual world eyetracking paradigm to investigate sentence processing in German by near-native English-German L2 users. The sentences in his experiment contained gender-marked articles that served as a cue for the upcoming noun. The L2 users did not use these cues to the same extent as German native speakers; this was interpreted as providing evidence for reduced predictive ability in L2 processing. In addition, Hopp (2013) found a correlation between consistency in gender assignment in a post-hoc production task and the 
extent to which word forms were anticipated on the basis of gender-marked articles. He argues that the level of L2 proficiency, translated into stability of lexical representations, mediates predictive processing.

Note that in both Hopp (2013) and Martin et al. (2013), the difference between the L1 and the target language with respect to the predictive cue is left undiscussed: Spanish does not have a similar phonological agreement rule (Martin et al., 2013), and English does not mark grammatical gender (Hopp, 2013). Hence, the absence of prediction effects in L2 processing could be caused by the lack of experience with specific (morpho)syntactic features in the L1. In L2 research, influence from the native language on L2 production and comprehension is a well-attested phenomenon; cross-linguistic influence and transfer have been shown to occur at all levels of language processing, and in a bidirectional fashion (from L1-L2-Ln and vice versa; see e.g., Jarvis \& Pavlenko, 2008; Odlin, 1989, 2005). Despite this commonly acknowledged effect of cross-linguistic influence, only very few studies have put forward the hypothesis that L2 predictive ability is modulated by the cross-linguistic similarity between people's native and second language, hence, their experience with specific forms and/or concepts via the L1. In a follow-up study of Martin et al. (2013), Foucart et al. (2014) investigated lexical prediction in French-Spanish bilinguals while reading constraining sentences in Spanish. In contrast to Martin et al., Foucart et al. did find anticipation effects in bilinguals: they found a larger N400 effect on the article when there was a mismatch between the gender of the article and the expected noun. Foucart et al. (2014) account for the difference in their findings in terms of typological relatedness between the bilingual's languages: French and Spanish exhibit a similar gender marking system, whereas such typological overlap is absent between English and Spanish. Dussias et al. (2013) studied typological distance in morphosyntactic prediction more systematically, comparing native Spanish speakers to both EnglishSpanish and Italian-Spanish bilinguals. While Italian encodes gender on articles similar to Spanish, English does not. They found that Italian-Spanish bilinguals exhibited a prediction effect similar to Spanish natives, but only for feminine gender. Given that the feminine article has the same realization in Spanish and Italian (la) while the masculine article does not (Spanish el vs. Italian il/lo), these data suggest that, in addition to having experience with a system of gender marking, specific L1-L2 form overlap in gender marking matters as well.

In a recent study, Hopp (2015) directly compares effects of semantic vs. morphosyntactic predictive cues in intermediate and advanced English L2 users of German: he investigated the role of German grammatical case marking as well as verb semantics (paradigm cf. Kamide et al., 2003). The comparison is based on the idea that, whereas native speakers use a variety of cues for prediction (contextual, pragmatic, semantic, lexical, morphosyntactic, prosodic), this may be different for L2 users. Hopp (2015) argues that acquiring L2 grammatical or morphosyntactic features is notoriously difficult in general, and that generating predictions on the basis of specifically those cues may be challenging in L2 processing. He shows that L2 users did not use morphosyntactic cues for prediction, irrespective of proficiency level, whereas all L2 learners did use the semantic cues encoded in the verb. His findings led him to conclude that it is easier to rely on semantic cues than to use morphosyntactic cues for the generation of predictions during incremental sentence processing. A similar conclusion regarding the role of verbal semantics in L2 processing is reached by, e.g., Koehne and Crocker (2015), looking at word learning mechanisms in adults. They conclude that verb semantics build on prior linguistic and world knowledge in which "any adult" should be an expert, making these cues highly reliable in sentence processing.

Again, it should be noted that the morphosyntactic cue (grammatical case) used by Hopp (2015) did not exist in the L2 users' native language (English), whereas the semantic cue (verbal semantics) existed in both their L1 and L2. Hopp (2015) does not mention this crosslinguistic variability within and between predictive cues. In fact, no studies on predictive processing so far have addressed cross-linguistic variation in semantics. The present study will be the first to target the effect of language experience on prediction by examining the role of experience with language-specific verbal semantics on predictive L2 processing. We will compare L2 users with different L1 backgrounds against the same L2 structure, where the L1s are chosen so as to differ with respect to the presence or absence of the critical feature. More specifically, we will compare native Dutch listeners to two groups of L2 Dutch users with L1s that display a cross-linguistic semantic contrast in the domain of caused motion, i.e., placement verbs.

\section{Placement events}

Placement events are acts of caused motion, i.e., acts in which a person causes an object to move from one place to another, e.g., putting a bottle on a table (for a large crosslinguistic project on placement, see Kopecka \& Narasimhan, 2012). The present study focuses on events of object placement on a flat surface providing support from below (e.g., a table or a chair). English uses the verb to put to describe such actions - French also encodes these events by means of a general placement verb (mettre). Contrastively, the Dutch verbal system distinguishes between zetten 'put.STAND' and leggen 'put.LIE', depending on the endstate of the object that is placed on the surface, i.e., the object's position. ${ }^{1}$ For each placement action, a Dutch speaker has to commit to one of these placement verbs and hence specify the object's position, which depends on a number of inherent features of the object as well as its configuration in relation to the ground. For instance, if an object has a natural base (such as a bottle), and the object rests on this base after being placed, zetten is used. If the object does not rest on its natural base after placement, leggen is used. Placement of objects without a natural base (e.g., a ball) can only be described with the verb leggen. Another relevant property for the verbal distinction is whether an

\footnotetext{
1 When describing a static location, a similar positional distinction is made by means of posture verbs, i.e., staan 'to stand' or liggen 'to lie' (Lemmens, 2002)
} 
object is extended horizontally (described with leggen) or vertically (described with zetten) (for a detailed description of the semantics of Dutch posture verbs, see Lemmens, 2002, 2006; see also Alferink \& Gullberg, 2014). Dutch also has a general placement verb that is underspecified for the object's position (plaatsen 'to place'). This general verb, however, is much less productive than its specified counterparts: of the combined frequency of occurrence of zetten, leggen, and plaatsen in the Corpus of spoken Dutch (CGN, 2004), the relative frequency of plaatsen is only $7 \%$. German (like other West-Germanic languages) makes a verbal distinction on the basis of the same semantic features as Dutch (hinstellen 'put.STAND' vs. hinlegen 'put.LIE'). Compared to English and French, both Dutch and German thus exhibit a higher degree of semantic specificity in the domain of placement verbs.

Acquiring such a specific verbal distinction is challenging. A commonly found pattern in the acquisition of this distinction is overextension: Narasimhan and Gullberg (2011) for example report an overextension of the verb leggen by 4 - and 5-year old children acquiring Dutch. In L2 production, Gullberg (2009) found that English L2 users of Dutch overgeneralize the verb zetten, as well as general action verbs like doen 'to do' when describing placement events; Berthele (2012) reports an overuse of the verb legen and the general action verb tun 'to do' in Romansh L2 users of German. Alferink and Gullberg (2014), investigating early French-Dutch bilinguals, report an overgeneralization of leggen in Dutch. Changing from a semantically specific to a more general verbal system, on the other hand, is also challenging. Gullberg (2011) shows that Dutch L2 learners of French performed target-like in their production of the general placement verb, but they showed transfer of a focus on object position in their accompanying gestures. A recent study by Cadierno, Ibarretxe-Antuñano, and Hijazo-Gascón (2016) also finds that L2 verb meaning reconstruction is difficult in both directions (from general to specific and vice versa), as evidenced in patterns of overgeneralization of specific verbs and use of general (nonplacement) action verbs. ${ }^{2}$

The above underlines that the properties of the L1 and the language user's experience with the L2 patterns strongly affect L2 production. This is in line with general notions of cross-linguistic influence in L2 processing (e.g., Odlin, 1989). In the current study, we focus on the role of language experience with semantically specific placement verbs in L2 sentence comprehension.

\section{The present study}

The research question we address in this paper is how crucial experience with a linguistically encoded concept is for predictive language processing. We investigate to what extent L1 Dutch listeners and L2 users of Dutch with different L1s generate predictions about upcoming referents on the basis of the semantic information encoded in

\footnotetext{
2 Note that there does not seem to be a straightforward or common pattern regarding the verb relied on for overgeneralization; previous studies hint at influences of target language frequency, as well as the existence of potential cognates in the L1 and their specific frequency of use in the native language system.
}

placement verbs. Crucially, the cross-linguistic variation in this domain allows for a direct investigation of the role of experience with a specific semantic contrast for such verbal predictions.

We use a visual world eye-tracking paradigm (Tanenhaus et al., 1995) to investigate anticipatory eye movements based on positional information as encoded in placement verbs in three experiments. In Experiment 1 , native Dutch participants are tested in their native language. Assuming that verbal semantics are used as predictive cues during sentence processing (cf. Altmann \& Kamide, 1999), we expect L1 Dutch listeners to narrow down their search space in the visual world to objects that match the position encoded in the placement verb (i.e., 'standing' objects for zetten, 'lying' objects for leggen). To address to what extent experience with language-specific verbal semantics is necessary for the ability to generate predictions in L2 processing, we will test two groups of highly proficient L2 users of Dutch in their L2. In Experiment 2, we will test a sample of late learners of Dutch with German as L1, a language that patterns with Dutch in the domain of placement verb semantics. In Experiment 3, we will test a sample of L2 users of Dutch who have either French or English as L1; both languages differ from Dutch in the placement domain, not encoding object position in placement verbs. If experience with the language-specific semantic contrast is key for predictive ability in L2 processing, we should find prediction effects in the first, but not in the second L2 group.

\section{Experiment 1: Native Dutch listeners}

\section{Method}

\section{Participants}

Twenty-five native Dutch speakers (mean age 22.9 years, range $18-28,4$ males) took part in the experiment. ${ }^{3}$ They were students at Radboud University in Nijmegen, the Netherlands and they received course credits or payment for participation. All participants had normal or correctedto-normal vision and normal auditory acuity.

\section{Materials}

Experimental materials consisted of 192 auditory sentences describing placement actions, combined with 32 visual displays containing four images, each appearing randomly in one of the four corners of a 22-in. computer screen. Images were construed using the open-source 3D animation software Blender (version 2.72), and contained common household objects that were placed on a surface (either a table or a chair). We used 64 objects to create 32 visual displays; each display contained one object in a lying position ( $\mathrm{L}$ object), one object in a standing position (S object), and one object in two positions (SL object), all placed on the same surface (cf. Fig. 1). In total there were 32 SL objects, occurring twice in the same display, as well as $16 \mathrm{~S}$ objects and $16 \mathrm{~L}$ objects, each of which occurred

\footnotetext{
3 Six participants had to be excluded from the analyses, due to severe tracking loss during the experiment (mean age of the sample eventually included in the analyses was 23.5 years).
} 

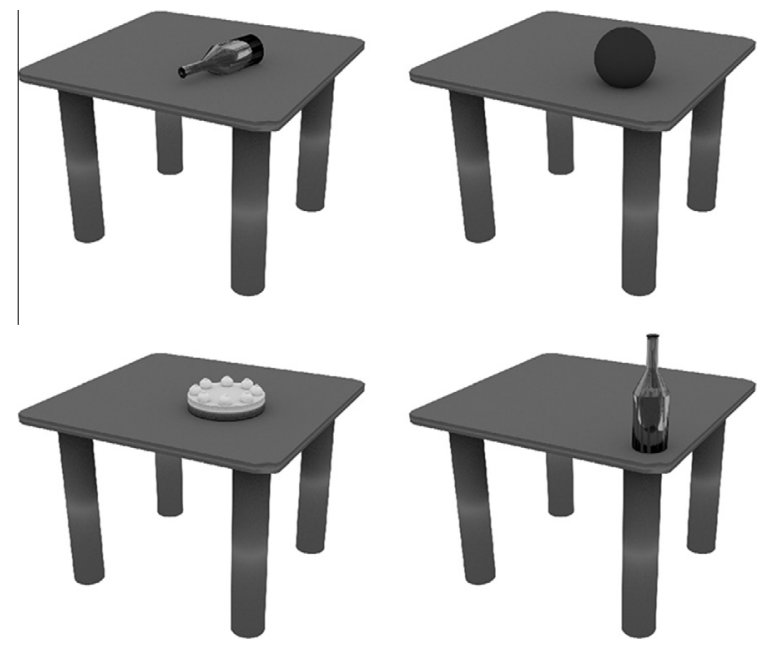

Fig. 1. Example of a display.

once in two displays, e.g., the ball and the cake occurred on a table in one display and on a chair in the other. The $16 \mathrm{~L}$ objects selected for the experiment resembled each other in that they can only be conceptualized and described as appearing in a lying position (hence using leggen/liggen) on the basis of their intrinsic properties (cf. section on placement events in the introduction); there was no such selection criterion for the $16 \mathrm{~S}$ objects (as there are no objects that can intrinsically only be conceptualized in a standing position).

Sentences started with a subject noun phrase (de jongen 'the boy', de man 'the man', de vrouw 'the woman' or het meisje 'the girl'), followed by the placement verb in simple past tense, an adverbial phrase, an object NP and a locational phrase, e.g., de jongen zette/legde/plaatste kort geleden een bal/taart/fles op de tafel the boy put.stand/put.lie/put recently a ball/cake/bottle on the table'. Sentences were recorded in a sound proof booth using Audacity; the speaker was a female native speaker of Dutch who used neutral intonation. Sentences were cut into separate sound files and onand offsets of subject, verb, adverb and object were marked using Praat (version 5.1, Boersma \& Weenink, 2015).

Each participant saw each display six times in combination with six different sentences, two of which contained zetten (followed by (a) an S object and (b) an SL object), two contained leggen (combined with (a) an L and (b) an SL object), and two contained plaatsen (followed by (a) an SL object and (b) either an $\mathrm{L}$ or an S object). ${ }^{4}$ This yielded a total of 64 sentences per verb. If the target object was an SL object, the display contained a contrast object (same object, different position), a position competitor (same position, different object), and a distracter object (different object, different position); if the target object was an S or an L object, the display contained a position competitor and two distracter objects. Within each display, there was no

\footnotetext{
${ }^{4}$ We included plaatsen as a control condition: since plaatsen is underspecified for position, there are no objects in the display that do not fit the selectional restrictions of this verb. As a result, plaatsen cannot be used as a cue for prediction.
}

semantic relation between the objects, and none of the objects were phonological competitors (none of the nouns started with the same phoneme). To make sure participants paid attention to both visual and auditory input during the experiment, a yes-no comprehension question followed the sentence in $10 \%$ of the cases. These were displayed in written form on the screen and concerned either an object (mis)match (e.g., stond de fles/gieter op de tafel? 'was the bottle/watering can on the table?') or a surface (mis)match (e.g., stond de fles op de tafel/stoel? 'was the bottle on the table/chair?'). The experiment consisted of 6 blocks of 32 sentences, such that each display occurred once per block. Block order was randomized per participant, as well as trial order within each block; the position of objects in the display was randomly generated per trial. Five practice trials preceded the experimental trials.

\section{Procedure}

Participants were tested in the eye-tracking lab at the Donders Centre for Cognition at Radboud University Nijmegen. All gave written consent to participate in this study (approved by the ethics committee of the Faculty of Social Sciences; ECG 2012-2711-059). Eye movements were recorded using an infrared remote eye tracker with a $500 \mathrm{~Hz}$ sampling rate (SensoMotoric Instruments, SMI, RED system). Participants sat about $70 \mathrm{~cm}$ from the monitor; a 9-point calibration was conducted for each participant at the beginning of the experiment.

Participants were verbally instructed to carefully listen to the sentences and look at the pictures on the screen, and they were told that they sometimes had to answer questions about what they saw and heard. The questions could be answered by pressing "yes" or "no" on a button box in front of them. The auditory stimuli were played over headphones, which participants were instructed to wear throughout the experiment. The experiment started with five practice trials, after which the participant had the chance to ask questions and the experimenter could give feedback. After this, a curtain between the experimenter and the participant was closed and the experiment started.

Each trial began with a fixation cross that remained on the screen for $500 \mathrm{~ms}$, after which the display appeared for $3000 \mathrm{~ms}$. After this preview participants listened to the target sentence while the display stayed on the screen. In $90 \%$ of the cases, the trial ended after sentence offset; the sentence was followed by a comprehension question $10 \%$ of the time. In those cases, the trial ended as soon as the participants answered the question with a button press.

After every block there was a short self-timed break. The experiment was followed by a language background questionnaire. The total procedure took about $50 \mathrm{~min}$.

\section{Data preprocessing and analysis}

For each participant, fixations in the four areas of interest (AOI) (the four objects) were computed for each trial, for the duration of the entire sentence including the three seconds preview, using the SMI software BeGaze.

To assess to what extent listeners make use of the positional information encoded in the verb to anticipate upcoming objects, fixation patterns were analyzed in the verbal prediction time window, ranging from $200 \mathrm{~ms}$ after verb onset until $200 \mathrm{~ms}$ after start of the object noun (as 
it takes about $200 \mathrm{~ms}$ to plan and initiate an eye movement in a four-object display, Salverda, Kleinschmidt, \& Tanenhaus, 2014). The mean duration of this window was $1535 \mathrm{~ms}$. For each trial and each participant, we calculated the total duration of AOI fixations within this time window, and we computed the logit-transformed odds ratio of standing $(\mathrm{S}+\mathrm{SL})$ over lying $(\mathrm{L}+\mathrm{SL})$ object fixations. ${ }^{5}$ We used a linear mixed effects regression model to predict the probability of standing over lying object fixations on the basis of the predictor Verb (zetten vs. leggen). The final model included random intercepts for participants and displays, as well as by-participant slopes for Verb. To assess whether a potential verb effect was not driven by either zetten or leggen exclusively, we also analyzed whether zetten and leggen significantly differed from plaatsen with a linear mixed effects model including two predictors for Verb (zetten vs. plaatsen, leggen vs. plaatsen) and the same random effects structure.

Second, to ensure participants' understanding of the meanings of zetten and leggen, we verified whether listeners readily distinguished between the standing and lying variant of the target object after hearing the target noun by measuring object fixations in the verb-object integration window, starting from target noun onset. Upon hearing the target noun, both $\mathrm{S}$ and $\mathrm{L}$ objects are uniquely identifiable in the display, even if the information from the verb is completely ignored. For SL objects (e.g., bottle), on the other hand, the target noun alone does not distinguish between the standing and lying variant (the same object is presented once in each position): listeners thus need to integrate the linguistic information retrieved from the verb with the noun in order to correctly identify the target referent. Therefore, eye gaze analyses in this time window were restricted to the zetten- and leggen-sentences containing SL objects. ${ }^{6}$ In order to explore potential latency differences between groups, we split up the verb-object integration window into three subsequent time windows:

- EARLY, ranging from target noun onset until target noun offset (mean duration $551 \mathrm{~ms}$ ).

- INTERMEDIATE, ranging from target noun offset until 500 ms after target noun onset.

- LATE, ranging from $500 \mathrm{~ms}$ after target noun onset until $1000 \mathrm{~ms}$ after target noun onset.

For our current purposes, comparing looks to the standing and lying variants of SL objects in the verb-object integration window is most relevant (hence disregarding looks to position competitors and distracter objects). Therefore, we first calculated for each trial and each participant the

\footnotetext{
${ }^{5}$ Looks outside the four areas of interest (corresponding to white space fixations) were disregarded in the analyses. To ensure that these white space fixations were independent of condition, we performed linear mixed effects analyses predicting the probability of white space fixations over AOI fixations on the basis of Verb Condition in each time window, for each language group. Results showed that the amount of looks outside the AOIs do not differ between any of the verbs in any time window for any of the 3 participant groups (all p's > .15).

${ }^{6}$ Note that the result of a placement event cannot be underspecified for position, even if the event itself is described with plaatsen: the object in the visual world is necessarily either 'lying' or 'standing' on a surface. For that reason, plaatsen-sentences were disregarded in this time window.
}

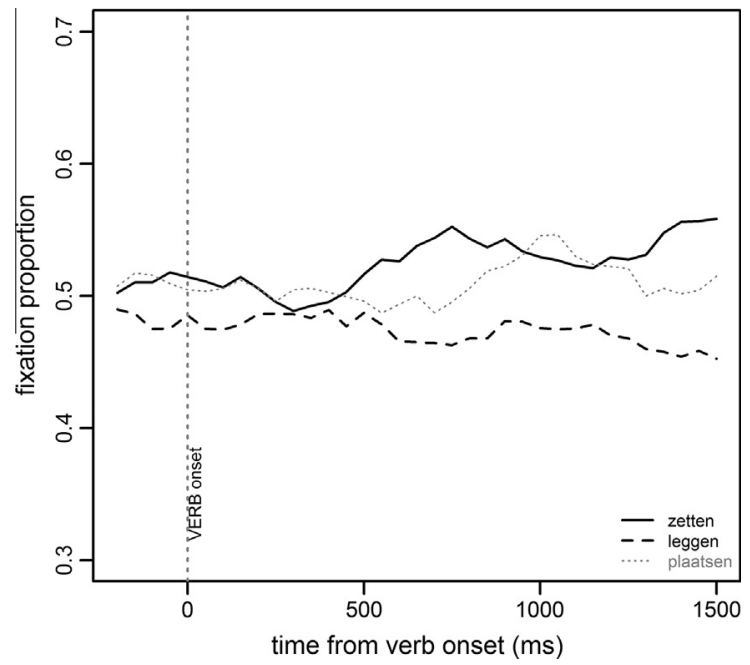

Fig. 2. Proportion of standing object fixations from verb onset in Dutch native listeners.

total duration of SL object fixations within each time window. Next, we computed the logit-transformed odds ratio of standing over lying SL object fixations for each time window. Again, we used linear mixed effects regression models to predict the probability of standing over lying SL object fixations on the basis of our predictor Verb (zetten vs. leggen); unless indicated otherwise, the statistical models included random intercepts for participants and objects, as well as by-participant slopes for Verb.

\section{Results}

\section{Comprehension questions}

Participants' accuracy on the comprehension questions was on average $94.7 \%(M=30.3[S D=1.86]$ out of 32 questions correct), ensuring that attention was paid to the stimuli.

\section{Verbal prediction}

Fig. 2 shows the mean fixation proportion of standing objects from the onset of the verb zetten (straight lines), leggen (dashed lines) and plaatsen (dotted gray lines) per $50 \mathrm{~ms}$ time bin for Dutch native listeners. Note that looks to standing $(\mathrm{SL}+\mathrm{S})$ objects and lying $(\mathrm{SL}+\mathrm{L})$ objects are complementary in our displays (see footnote 5), i.e., a higher proportion of standing object fixations means a lower proportion of lying object fixations.

It can be seen from Fig. 2 that the straight and dashed lines start to diverge soon after verb onset, indicating an increasing proportion of standing object fixations after hearing zetten, and a decreasing proportion of standing (thus an increasing proportion of lying) object fixations after encountering leggen. In other words, native listeners anticipate objects in the display that match the position encoded in the verb. The results from the statistical analysis corroborate this, showing a significant main effect of $\operatorname{Verb}(\beta=0.73, S E=0.29, p<.05)$ : the probability of fixating a standing object after hearing zetten is (inverse log of 0.73) about twice the probability of fixating one of the standing 

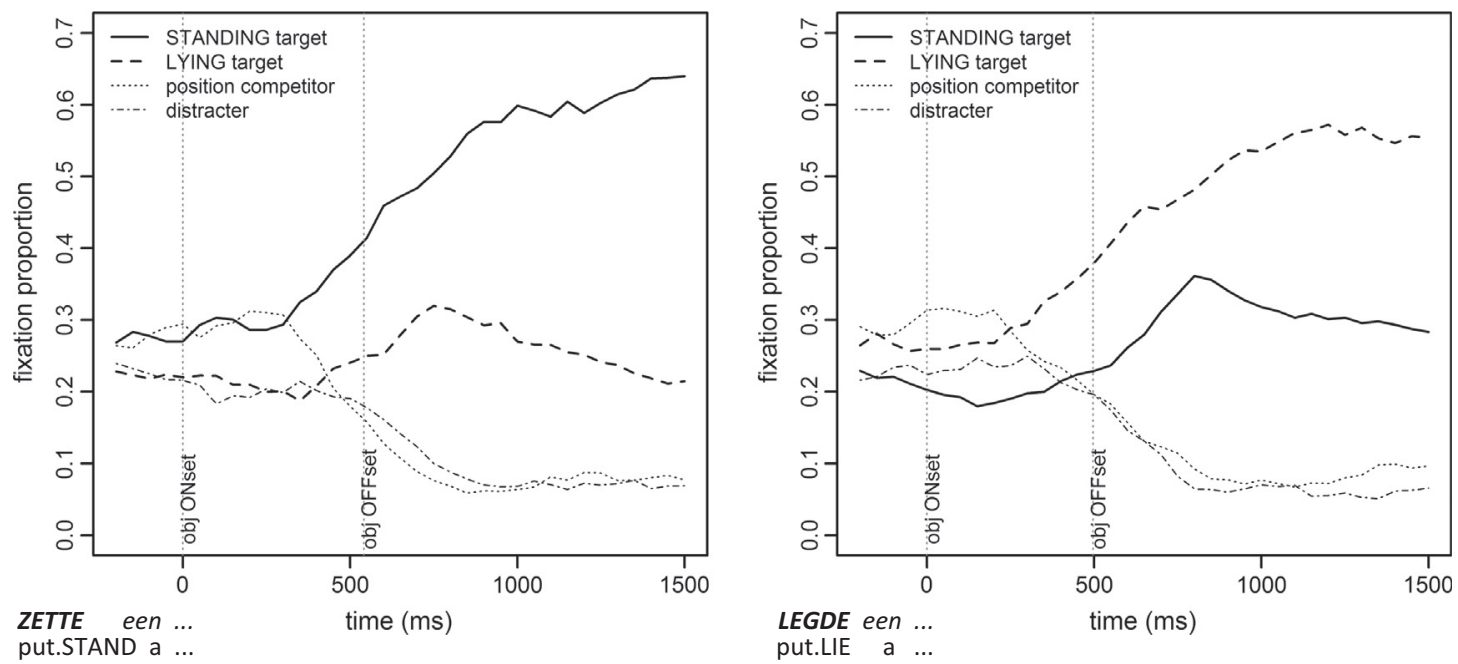

Fig. 3. Proportion of object fixations from SL object onset after zetten (left panel) and leggen (right panel) in Dutch native listeners.

objects after hearing leggen. Additional analyses show that the probability of fixating standing objects after hearing zetten is significantly higher than after hearing plaatsen $(\beta=0.31, S E=0.15, p<.05)$, whereas the probability of fixating standing objects after hearing leggen was significantly lower than after hearing plaatsen $(\beta=-0.42$, $S E=0.15, p<.05)$.

\section{Verb-object integration}

Fig. 3 shows the proportion of object fixations timelocked to target noun onset when preceded by the verb zetten (left panel) and leggen (right panel) for sentences containing an SL object. ${ }^{7}$ It can be seen that Dutch native listeners quickly differentiate between target object and position competitor, which are the most probable referents based on the selectional restrictions of the verb. Moreover, the patterns in Fig. 3 suggest a rapid integration of the incoming linguistic input with the previously encountered verbal information: the proportion of looks to the target object keeps increasing throughout the time window, whereas the proportion of contrast object fixations (same object, different position) starts decreasing about $300 \mathrm{~ms}$ after target noun offset. The statistical analysis confirms that the verb significantly influences the probability of fixating the target object over the contrast object in all three time windows (EARLY: $\beta=1.79, S E=0.56, p<.01$; INTERMEDIATE: $\beta=2.86, S E=0.80, p<.01$; LATE: $\beta=4.36, S E=1.04$, $p<.001)^{8}$

\footnotetext{
${ }^{7}$ Note that it is not possible to deduce what happens from the end of the verbal prediction time window until object onset from Figs. 2 and 3: Different subsets of the data are plotted, and data are time-locked differently. In the prediction window, fixations are time-locked to verb onset, meaning that object onsets are variable, i.e., the end of the verbal prediction window does not neatly correspond to object onset in the integration window. For a complete overview of AOI fixations across the entire sentence split up by group, verb and sentence type, we refer the reader to the supplementary materials.

${ }^{8}$ For the INTERMEDIATE and LATE time window analyses, final models included random intercepts for participants and objects, as well as byparticipant and by-object slopes for Verb.
}

\section{Discussion}

Findings show that native Dutch listeners launch anticipatory looks toward objects matching the position encoded in the placement verb soon after hearing the verb, and before encountering the noun. Our results extend the findings of Altmann and Kamide (1999) who showed the predictive power of verb semantics at a more general level (e.g., to eat, to smoke to predict edible or smokable objects, respectively) to the specific semantic domain of caused motion, i.e., placement. Importantly, this domain is subject to cross-linguistic diversity in semantic specificity, which we use to study the role of experience in prediction. Moreover, we show that for prediction effects to be established, the predictive cue need not unambiguously lead to one specific referent in the visual world, which was the case in Altmann and Kamide (1999): in the present case, each display contained two objects obeying the selectional restrictions of the verb. Narrowing down the search space to two possible referents in the visual world proved beneficial for the integration of the object into the sentence: listeners tended to fixate the SL object in the target position more often than the SL object in the other position already in the EARLY integration time window. Our findings thus provide evidence that the contents of predictions can also concern perceptual features of objects. This is in line with Rommers et al. (2013) who show that listeners already activate the shape characteristics of the target object before having encountered the noun.

Having established that placement verbs are indeed used as predictive cues in Dutch sentence processing, we will continue by investigating to what extent this predictive behavior is found in L2 users of Dutch.

\section{Experiment 2: L2 Dutch listeners with German as their native language}

The same visual world eye tracking experiment was conducted with a sample of high proficient L2 Dutch 
participants with German as their native language. Bear in mind that German closely resembles Dutch in the placement domain in that it also verbally encodes object position. If the German L2 users of Dutch do not display anticipation effects in relation to position information, we can assume that specific linguistic experience does not unequivocally lead to semantic prediction in a nonnative language. If we do find prediction in these participants, either general L2 experience or experience with the specific semantics of placement verbs may lead to native-like predictive ability.

\section{Method}

\section{Participants}

Twenty-two L2 users of Dutch with German as their native language (mean age 22.6 years, range 19-27, 3 males) took part in this experiment. ${ }^{9}$ One participant was an early bilingual speaking both German and Dutch since birth. All participants in this group were studying at Radboud University at the moment of testing. They received course credits or payment for participation. All participants had normal or corrected-to-normal vision and normal auditory acuity. Their L2 proficiency was assessed using LexTALE (Lemhöfer \& Broersma, 2012) (mean score 71, SD 8.5, range 52-82); the average score converts to level B2 (upperintermediate level of proficiency) of the CEFR (Council of Europe, 2001). The German-Dutch L2 participants had resided in the Netherlands for on average 2 years (SD 1.5 years) and they were enrolled as students of a Dutch university, using Dutch as the main language of communication and courses were instructed through the medium of Dutch. The late bilinguals had an average length of exposure to Dutch of 3.2 years (SD 4.3 years).

\section{Materials and procedure}

The experiment and procedure was exactly the same as described above for Experiment 1, with the addition of the LexTALE test of proficiency in Dutch at the end of the experimental session.

\section{Data preprocessing and analysis}

For the German-Dutch L2 group, we analyzed the same time windows as for the native listeners. We built similar linear mixed effects regression models with Verb as a fixed predictor; the final models included the same random effects structure as the native speaker models. To compare the L2 data to the native listeners, we built linear regression models for all time windows on the basis of the fixed predictors Verb, Language Group and their interaction; unless indicated otherwise, the final models included random intercepts for participants and displays (prediction window)/objects (integration windows), as well as byparticipant slopes for Verb.

\footnotetext{
9 Three participants were excluded due to poor recording quality. The data on proficiency and language use reported in this section concern the participants who were eventually included in the analyses (mean age of this sample was 22.8 years).
}

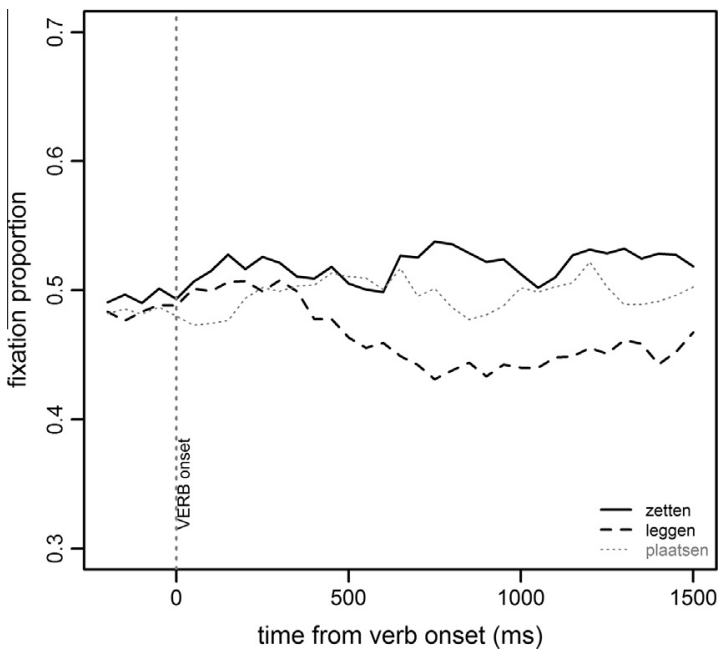

Fig. 4. Proportion of standing object fixations from verb onset in German-Dutch L2 listeners.

\section{Results}

\section{Comprehension questions}

Participants' accuracy was on average 94.9\% $(M=30.4$ $[S D=1.83]$ out of 32 questions answered correctly); there was no significant difference in accuracy between German-Dutch L2 users and native speakers $(\beta=-0.05$, $S E=0.42, z=-0.03, p=.91$, n.s.).

\section{Verbal prediction}

Fig. 4 shows the mean fixation proportions of the two standing objects time-locked to verb onset for GermanDutch L2 listeners. It can be seen from the figure that the German-Dutch L2 pattern closely resembles the native pattern. The proportion of standing object fixations starts increasing for zetten and decreasing for leggen (corresponding to an increase in lying object fixations) quickly after verb onset. This is confirmed by the results from the statistical analyses: the results revealed no significant Verb by Language Group interaction effect $(p=.50)$ : German-Dutch L2 listeners do not significantly differ from native listeners in anticipating objects that match the position encoded in the placement verb. Indeed, analysis of the German-Dutch L2 data alone reveals a significant main effect of Verb in this time window $(\beta=0.50, S E=0.20, p<.05)$. In the additional analyses, we found no significant Verb by Language Group interaction effect $(p=.58)$ : the L2 data analyses alone revealed that the probability of fixating standing objects after hearing zetten was significantly higher than after hearing plaatsen $(\beta=0.25, S E=0.11, p<.05$ ); the difference between leggen and plaatsen was marginally significant $(\beta=-0.24, S E=0.12, p=.06)$.

\section{Verb-object integration}

Fig. 5 shows the German-Dutch L2 users' object fixation proportions time-locked to target noun onset when preceded by the verb zetten (left panel) and leggen (right panel). It can be seen that L2 listeners predominantly fixate 

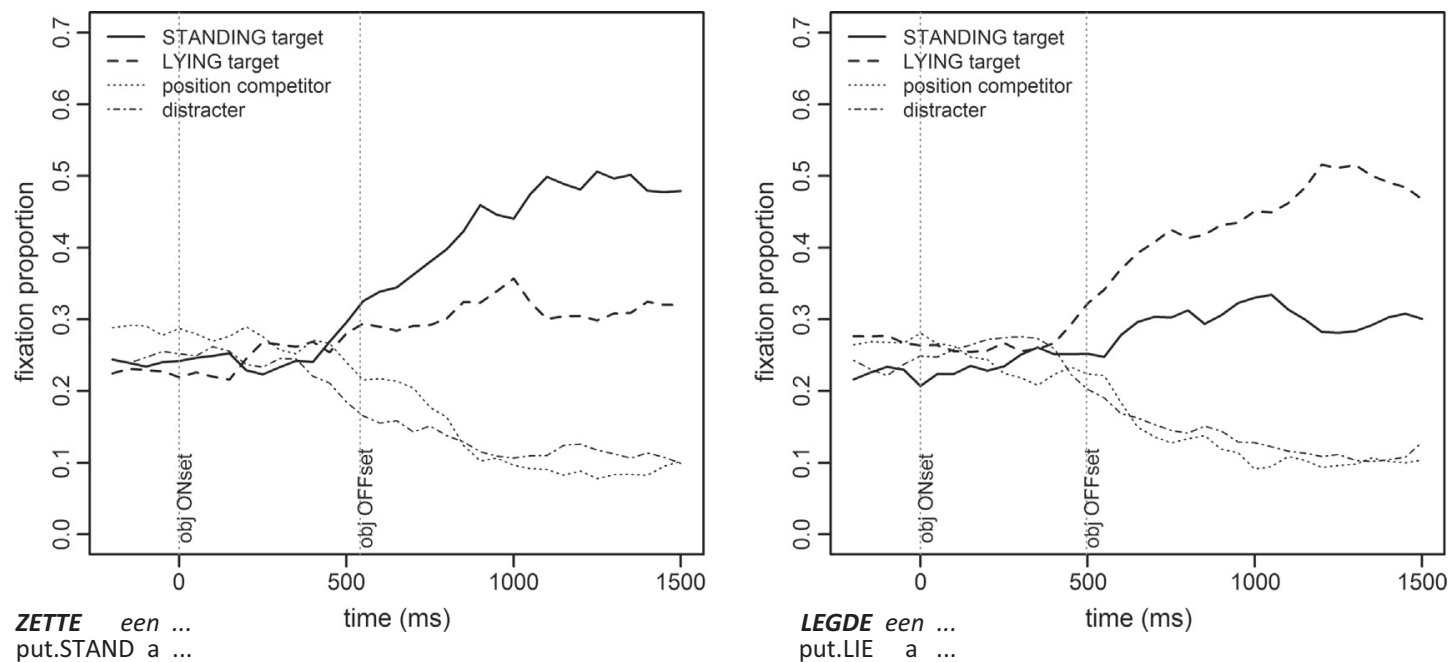

Fig. 5. Proportion of object fixations from SL object onset after zetten (left panel) and leggen (right panel) in German-Dutch L2 listeners.

the SL object after the onset of the target noun, although the $\mathrm{L} 2$ pattern is not as pronounced as the native pattern.

Compared to the Dutch native listeners, the GermanDutch L2 listeners show delayed integration of the critical noun with the prior verbal information. Whereas native listeners fixate the target object in the target position immediately after the onset of the critical noun, Fig. 5 suggests that L2 listeners need a bit more time to disambiguate between the two positional variants of the target object: they take longer to move their visual attention away from the contrast object (i.e., the lying variant of the SL object after hearing zetten and the standing variant after hearing leggen). Nevertheless, they do seem to integrate the incoming noun with the preceding verbal information, as they correctly distinguish between the two variants of the SL object on the basis of the preceding verb. This is confirmed by the statistical analyses of the verb-object integration time windows. We found a significant Verb by Language Group interaction effect in the EARLY time window $(\beta=1.62, S E=0.76, p<.05)$; the verb effect on the probability of fixating target over contrast objects is significantly larger for Dutch native speakers than for German-Dutch L2 users. In the two later time windows, the interaction effect is marginally significant (INTERMEDIATE: $\beta=1.68, S E=0.96, p=.09$; LATE $^{10}: \beta=2.21, S E=1.19$, $p=.07)$. Analyses of the German data alone show no significant main effect of Verb in the EARLY time window $(p=.70)$ and a marginally significant Verb effect in the INTERMEDIATE window $(\beta=1.15, S E=0.62, p=.08)$; the verb does significantly influence the probability of fixating target over contrast objects in the LATE time window $(\beta=2.23$, $S E=0.64, p<.01)$. In other words, although German-Dutch L2 users readily make use of the verbal information to disambiguate between object positions, this pattern emerges later compared to native listeners.

\footnotetext{
10 The final model of the LATE time window included random intercepts for participants and objects, by-participant slopes for Verb and by-object slopes for Language Group.
}

\section{Discussion}

The results from Experiment 2 show that GermanDutch L2 listeners generate predictions about upcoming referents on the basis of verbal information in their L2 (Dutch). This excludes the possibility that L2 comprehension is fundamentally different from native language comprehension, in the sense that second language processing is more or less non-predictive even at high proficiency levels (cf. Martin et al., 2013; overview in Kaan, 2014). At this point, however, we do not know yet whether prediction is part of L2 processing by default or whether there is a mediating role for experience with the specific L2 predictive cue, i.e., the semantic specificity of placement verbs.

We furthermore found differences between native and non-native listeners in integrating the noun with the predicted verbal information. For native listeners, integrating the noun with the preceding information was facilitated by their anticipatory behavior: the early positional distinction made it easier to disambiguate between the two variants of the SL object upon encountering the critical noun rapidly. In the $\mathrm{L} 2$ sample, the positional information from the verb seems to be used less efficiently as the effect of verb in integration processing emerged somewhat later, i.e., after target noun offset. The L2 listeners seem to distribute their attention over the target as well as the position competitor in the beginning of the integration window, suggesting a higher degree of uncertainty about the incoming speech signal.

\section{Experiment 3: L2 Dutch listeners with French/English as native language}

To shed light on the role of language experience in L2 prediction the same visual world eye tracking study in Dutch was conducted with participants speaking either French or English as their native language. Recall that in both French and English, placement verbs do not encode information regarding object position; rather, there is one general placement verb that is underspecified with respect 
to position. In the domain of interest for the present study, these two languages pattern similarly, allowing the grouping of French and English participants with a similar high proficiency in their second language Dutch.

Controlling for level of proficiency in Dutch (similar to the German L2 group), if we find that this group also anticipates object position on the basis of placement verb semantics, we have grounds to assume that specific language experience does not play a significant role in predictive processing. If, on the other hand, the L2 French/English L2 users of Dutch do not show verbal prediction effects, we may conclude that experience with a specific semantic contrast through the native language is crucial for predictive L2 sentence processing.

\section{Method}

\section{Participants}

Twenty-one L2 users of Dutch (mean age 28.7 years, range 20-41, 10 males) took part in this experiment (9 French, 12 English native speakers). ${ }^{11}$ Two participants in the group were early bilinguals of English and Dutch. Participants were recruited at Radboud University; all were students or staff members at university at the time of testing. They received payment for participation. All participants had normal or corrected-to-normal vision and normal auditory acuity.

The proficiency of the L2 group was again obtained using the Dutch version of LexTALE (Lemhöfer \& Broersma, 2012) (mean score 70.94, SD 14.05, range 4391 ); the average LexTALE score converts to B2 (upper intermediate level of proficiency) according to the CEFR. ${ }^{12}$ In addition, their language background was documented with a questionnaire. The L2 participants had resided in the Netherlands for on average 5.5 years (SD 6.1 years) and they were either taking university courses in Dutch, or they worked at the university using Dutch as the main working language. Their average length of exposure to Dutch was 6.2 years (SD 6 years). ${ }^{13}$

\footnotetext{
${ }^{11}$ Five participants were excluded because of poor recording quality. The data on proficiency and language use reported here concern the participants which were eventually included in the analyses (nine English and seven French native speakers; mean age of this sample was 28 years; an ANOVA showed that this sample had a slightly higher mean age than the German L2 group $(F(1,33)=10.00, p<.05)$. Given the scarcity of highly proficient English and French L2 users of Dutch, it was unfortunately impossible to fully match the two L2 groups on age. Although previous research has reported age effects on predictive processing, these studies compared 18-35 year old students with 60+ elderly people (moreover, not all reported age effects point in the same direction: e.g., Huettig \& Janse, 2016 report only a small effect of age, hinting at better predictive ability in older adults). As the age difference between the L2 groups we tested is much smaller than those tested previously, we do not expect this to have any effect on our results (the French/English L2 sample contained 4 participants over 30 and under 40 , whereas the German participants were all aged between 20 and 30 ).

12 A comparison of lexTALE scores to those in the German-Dutch L2 group showed no significant difference $(F(1,33)=0.0002, p=.99)$ : both groups have upper-intermediate proficiency in the target language (Dutch).

${ }^{13}$ The length of residence in the Netherlands was significantly longer for the French/English L2 group than for the German L2 group $(F(1,33)=5.97$, $p<.05)$; there was no statistical difference concerning years of exposure to the Dutch language $(F(1,33)=2.95, p=.09)$.
}

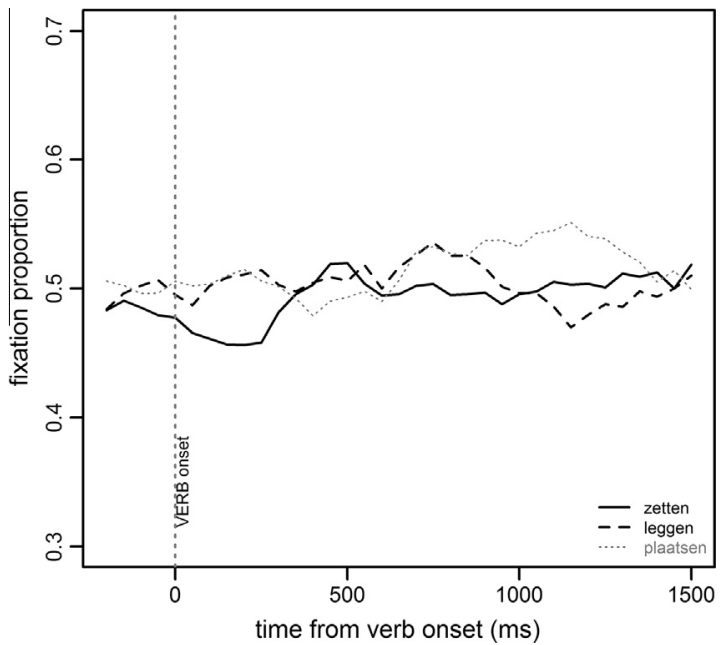

Fig. 6. Proportion of standing object fixations from verb onset in French/ English-Dutch L2 listeners.

\section{Materials and procedure}

The experiment and procedure was exactly the same as described above for Experiment 2.

\section{Data preprocessing and analysis}

We analyzed the same time windows as for the native listeners and the German-Dutch L2 group. We built similar linear mixed effects regression models with Verb as a fixed predictor; the final models included the same random effects structure as the native speaker and German L2 models.

To statistically compare the French/English-Dutch L2 data to the native listeners, we built linear regression models for all time windows on the basis of the fixed predictors Verb, Language Group and their interaction; all final models included random intercepts for participants and displays (prediction window)/objects (integration windows), as well as by-participant slopes for Verb, unless indicated otherwise.

\section{Results}

\section{Comprehension questions}

Accuracy was on average $89.5 \%(M=28.6[S D=3.0]$ out of 32 questions answered correctly), which was significantly lower than the accuracy of the Dutch L1 group $(\beta=-0.92, S E=0.33, p<.05) .{ }^{14}$ Despite this difference, the overall high accuracy in all groups ensured that all participants were paying a high degree of attention to the visual and auditory input.

\section{Verbal prediction}

Fig. 6 presents the mean proportion of standing object fixations time-locked to verb onset for French/English-

\footnotetext{
14 A comparison to accuracy rates in the L2 German-Dutch group also shows a significant difference $(\beta=-0.91, S E=0.39, p<.05)$. Note that none of the comprehension questions concerned a (mis)match with respect to the position of the object; therefore, the accuracy difference is not indicative of a difference in understanding of placement verbs.
} 

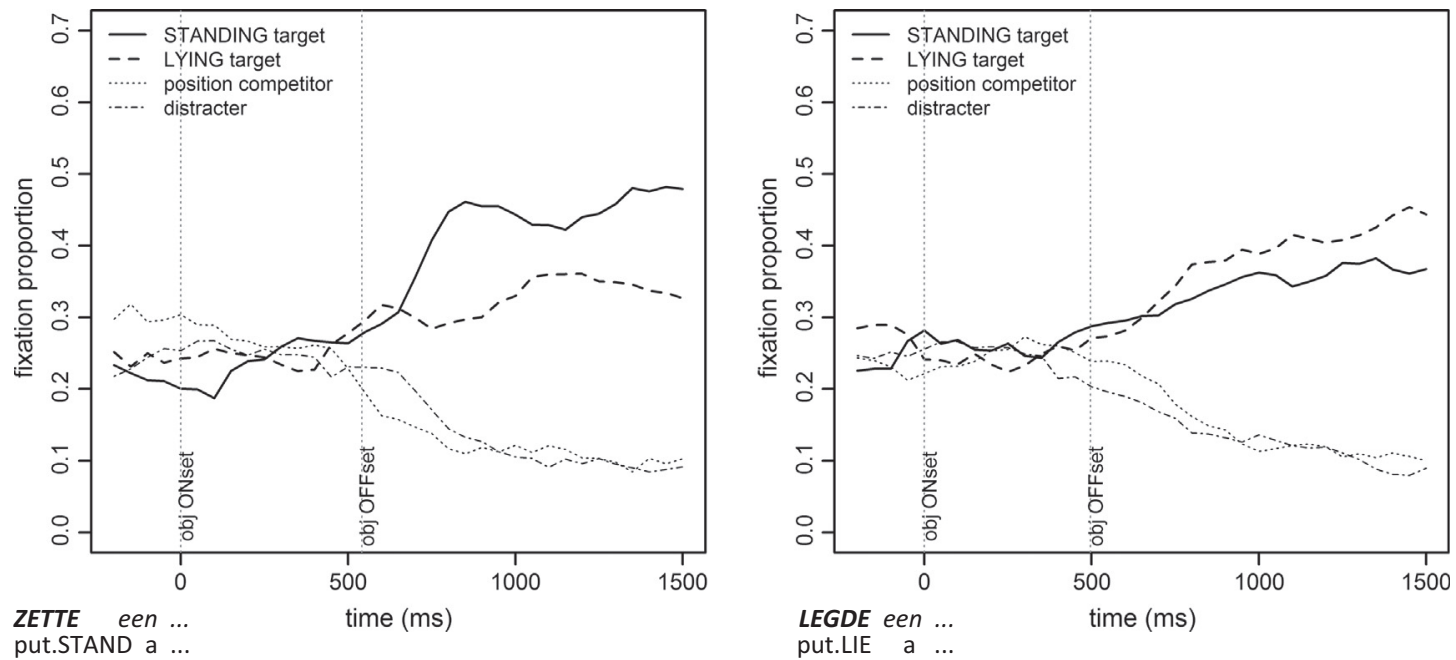

Fig. 7. Proportion of object fixations from SL object onset after zetten (left panel) and leggen (right panel) in French/English-Dutch L2 listeners.

Dutch L2 listeners. Unlike the native listeners and the German-Dutch L2 users, the French/English-Dutch L2 group does not show anticipatory looks to objects matching the selectional restrictions of the verb: soon after verb onset, the ratio of standing-to-lying object fixations is about one-to-one, and it is equal for both verbs.

A comparison between French/English-Dutch L2 users and native listeners confirms the visual difference: the verb effect is significantly larger for native listeners than for French/English-Dutch L2 users $(\beta=0.83, S E=0.33$, $p<.05)$. Indeed, the results of the French/English-Dutch L2 data analyses show that the main effect of Verb is not significant $(p=.62)$ : before encountering the target object, French-Dutch L2 listeners do not look significantly more often to objects matching the position encoded in the placement verb.

Additional analyses also showed that differences between the three verbs were significantly smaller for French/English-Dutch L2 users than native listeners: model comparison showed that including the $3 \times 2$ interaction effect significantly increased the predictive power of the linear mixed effects model $\left(X^{2}(2)=6.51, p<.05\right)$. Analyzing the French/Dutch L2 data alone, we found that neither zetten $(p=.69)$ nor leggen $(p=.64)$ significantly differed from plaatsen in affecting the probability of fixating standing over lying objects.

\section{Verb-object integration}

Fig. 7 shows the object fixation proportions time-locked to target noun onset when preceded by the verb zetten (left panel) and leggen (right panel).

The data suggest that French/English-Dutch L2 listeners' eye gaze patterns are less strongly affected by the preceding verb than those of native listeners. The straight and dashed black lines do start to diverge in the expected direction, showing that participants do integrate the target noun with the verbal information, but the positional distinction emerges well after the target noun has been fully encountered. A comparison with native listeners confirms that the Verb effect is significantly smaller for French/
English-Dutch L2 users in all three time windows (EARLY: $\beta=2.15, \quad S E=0.73, \quad p<.01 ; \quad$ INTERMEDIATE: $\beta=1.25$, $S E=0.46, p<.05$; LATE: $\beta=1.56, S E=0.59, p<.05) .{ }^{15}$ Analyses of the French/English-Dutch L2 data alone show that the verb does not significantly alter the probability of fixating the object in target position over the object in the contrast position in the EARLY $(p=.51)$ or the INTERMEDIATE $(p=.48)$ time window. We did find a significant main effect of Verb in the LATE time window ( $\beta=1.35, S E=0.51, p<.05)$; the probability of fixating the standing over the lying variant of the SL object is significantly larger after hearing zetten than after hearing leggen.

\section{Discussion}

The results of Experiment 3 show that French/EnglishDutch L2 users do not make use of specific placement verb semantics to anticipate the position characteristics of upcoming objects during L2 sentence processing. These findings suggest that familiarity with a semantic contrast in the native language is crucial in order to be able to generate semantic predictions in a second language.

Looking at integration processes, French/English-Dutch L2 users do correctly identify the target object after noun onset, but they do so relatively late. The data suggest that this is due to their lack of experience with the specific placement verb semantics: whereas native Dutch participants distinguish between position-matching and position-mismatching target objects quickly after encountering the noun, French/English-Dutch L2 listeners need more time to integrate the target noun with the positional information encoded in the placement verb. This additional processing time may be required because object position had not been anticipated earlier on in the sentence (upon encountering the verb). Importantly, though, the fact that there was a significant effect of verb on target object fixations about a second after target noun offset

\footnotetext{
15 The LATE model included random intercepts for participants and objects, as well as by-participant and by-object slopes for Verb.
} 
shows that the French-English L2 participants were fully aware of the meaning of the placement verbs. The lack of a prediction effect can thus genuinely be attributed to a lack of experience in using the semantic information encoded in these verbs to anticipate upcoming speech, rather than a lack of understanding of the verbs themselves.

To further ensure a high level of understanding of the verbs' meanings, we designed an additional control experiment testing proficiency on placement verb production and comprehension, which was administered with a sample of L2 French/English-Dutch participants $(N=24)$, highly comparable in terms of age, language background and Dutch language proficiency to the participants studied in Experiment 3 (10 males; mean age 28.3 years; lexTALE mean score 70.9). ${ }^{16}$ The comprehension task involved the selection of one of 4 pictures (a display from the original experiment) to match sentences describing a placement action (also from the eye tracking experiment). The production part consisted of selecting the correct verb (zetten or leggen) to complete a sentence from the original experiment, accompanied by a picture of an object on a surface (again selected from the displays used in the original experiment). Comprehension accuracy was high at on average $82.4 \%$ ( $M=23.1$ out of 28 displays correctly matched to a sentence; $S D=4.33$ ), with no significant difference between zetten $(85.7 \%$ correct) and leggen items $(79.1 \%)(F(1,23)=2.42$, $p=.13)$. A similarly high accuracy score was obtained for the production task ( $84.6 \% ; M=13.5$ out of 16 items with the correct verb chosen; $S D=1.61)$. Comparing accuracy on SL vs. L objects showed that SL objects (99.0\% correct) rendered better performance than L objects (accuracy 70.3\%; $F$ $(1,23)=40.9, p<.001)$, suggesting that French/English L2 participants have a specific degree of difficulty with the $\mathrm{L}$ objects. Recall that, intrinsically, the L objects used in the experiment can only be conceptualized and described as appearing in lying position, i.e., using leggen. The learning difficulty for these participants may relate to inherent object properties (the fact that only objects with a natural or functional base would allow use of zetten) and the rather 'arbitrarily' associated linguistic patterns, rather than understanding the semantics of the placement verbs themselves. $^{17}$

In sum, findings from Experiment 3 as well as an additional experiment show that French/English L2 Dutch par-

\footnotetext{
${ }^{16}$ A comparison of lexTALE scores of the original French/English L2 sample and the sample tested in the additional experiment showed no significant difference $(F(1,38)=.077, p=.80)$.

17 To address one of the reviewers' concerns about the validity of merging French and English participants, we compared their performance on placement verb comprehension and production. In comprehension, we did not find a significant main effect of Language $(F(1,22)=1.10, p=.31)$, nor an interaction of Language with $\operatorname{Verb}(F(1,22)=1.01, p=.33)$. Analyses on the production data also showed no main effect of Language $(F(1,22)$ $=2.43, p=.13$ ), but we did find a marginally significant interaction of Language by Object type $(F(1,22)=3.69, p=.07)$. This tendency suggests that English participants may have had more difficulty choosing the correct verb (i.e., leggen) for the 'arbitrary' L objects (62.5\%) than French participants (76.9\%). As production performance on SL objects was extremely high for both English (100\%) and French (98.1\%) participants we have no reason to assume that French and English participants differ in their understanding of the semantics of the placement verbs per se.
}

ticipants are aware of the meaning of Dutch placement verbs. However, their lack of experience with this specific semantic contrast prevents them from using this information as a predictive cue.

\section{General discussion}

This study addressed a central question regarding prediction in incremental language comprehension: to what extent does language experience modulate predictive sentence processing? We approached this question by investigating the extent to which placement verbs, displaying cross-linguistic variation in semantic specificity, are used as predictive cues in L2 sentence processing. GermanDutch L2 users, familiar with the encoding of object position in German placement verbs, were found to anticipate positional characteristics of objects upon encountering the Dutch placement verb to the same extent as native Dutch listeners. French and English L2 users of Dutch, lacking this positional distinction in their L1 verbal system, did not anticipate object position.

To our knowledge, this is the first study to investigate effects of cross-linguistic variation in verbal semantics in predictive L1 and L2 processing. Whereas verbal semantics have been shown to be used as a predictive cue in native sentence processing (as first shown by Altmann \& Kamide, 1999), and considered to be a fundamental cue regardless of language experience and background (Hopp, 2015; Koehne \& Crocker, 2015), our findings call for a refinement of this view: Verbal semantics serve as predictive cues in L2 processing, but only if language users have enough experience with the semantic distinction through their native language. The German-Dutch L2 results illustrate that prediction and integration are different aspects of language processing, each being susceptible to L2 effects in their own way: whereas predictions are generated effortlessly (given a lifetime of experience with the predictive cue), integration of the target noun with previously encountered verbal information suffers from a delay in L2 users compared to native listeners. Delayed processing is often reported as characteristic of L2 processing (Hahne, 2001; Hopp, 2010; Weber-Fox \& Neville, 1996), but our data show that a delay in processing need not go hand in hand with inability to generate predictions.

Our findings nicely illustrate that cross-linguistic comparisons are an effective way of shedding light on general language processing mechanisms (cf. Chang, Baumann, Pappert, \& Fitz, 2014; Flecken, Gerwien, Carroll, \& von Stutterheim, 2015; Jaeger \& Norcliffe, 2009, for language production). Moreover, our study provides a methodological improvement by testing participants in their second language rather than their native language. This allowed for a cross-linguistic comparison while using identical linguistic materials, which made it possible to overcome difficulties arising from cross-linguistic variation outside the domain under investigation. Because the linguistic input was identical for all participants, differences in anticipatory behavior can only result from differences at the group level. Crucially, the L2 groups were carefully matched for general L2 proficiency and exposure: both samples were equally (high) proficient in the target language; in fact, 
the French/English L2 group had been immersed in the L2 speaking community for a slightly longer period of time than the German-Dutch L2 participants. Given their highly comparable language backgrounds, we attribute the difference in predictive processing to a difference in specific linguistic experience, i.e., the relevant positional distinction being present in the native language system or not, rather than a difference in general L2 proficiency or immersion. Analyses of verb-noun integration as well as findings from the additional experiment with French/English L2 users of Dutch, targeting accuracy on placement verb comprehension and production specifically, underline this by showing a high level of performance in this domain. We can thus rule out that the lack of prediction is directly related to low general L2 proficiency, or to a lack of understanding of the semantic contrast encoded in Dutch placement verbs.

Studies on individual differences in language processing have shown that variability in sentence processing performance is determined by linguistic expertise of various types (e.g., Huettig \& Brouwer, 2015; Farmer et al., 2011; Kuperberg \& Van Dyke, 2011; Mani \& Huettig, 2012; Mishra et al., 2012). If we take native language background as a proxy for linguistic experience in the semantic domain of placement, our data corroborate these findings. Our results indicate that using L2-specific semantic content for prediction is difficult when long-term previous experience with this content is lacking. From L2 production studies it is known that when the L1 and the L2 encode the same content (e.g., an event of placement or motion) with a different level of specificity or granularity, it is hard to adjust, overrule or restructure the L1 ways of speaking (see e.g., Pavlenko, 2011; Jarvis \& Pavlenko, 2008). In some cases the L2 encodes different aspects of the same content compared to the $\mathrm{L} 1$, as a result of which $\mathrm{L} 2$ learners have to completely reconsider an existing semantic category. For example, in some languages motion verbs encode the manner of motion, whereas the path is encoded in motion verbs in others (cf. Talmy, 2000). Flecken, Carroll, Weimar, and Von Stutterheim (2015) studied L2 users performing a motion event description task; they found that even though participants performed almost target-like, they displayed increased attention to information that was only relevant to their L1 when preparing to speak in the L2. These findings fit the view that the native language leads to certain routines of information processing (cf. Slobin, 1996) which operate in a highly automatic fashion. If one has to be entrained to new routines of information processing, like French/English L2 users of Dutch who have to be familiarized with attending to the positional characteristics of objects, it will be challenging to arrive at the same level of automaticity.

The question is whether the (lack of) prediction effects in the current study can be exclusively ascribed to the semantics of the verb. Assuming that language users make simultaneous use of multiple sources of information for incremental sentence comprehension (as any constraint-based account of sentence processing does, e.g., MacDonald, 1994; Tanenhaus et al., 1995; for a review, see McRae \& Matsuki, 2013), participants in our experiment could use both the visual and the linguistic input to anticipate the upcoming object. With respect to the visual input, some objects could not be anticipated on the basis of their configurational characteristics with respect to the surface (the table/chair). Each display contained one $\mathrm{L}$ object, which could only be described with leggen given its intrinsic properties. These inherent object features are again only relevant for languages that make a positional distinction in their placement verbs (like Dutch and German). ${ }^{18}$ Put differently, using these semantic cues for prediction requires experience at two highly interrelated levels of processing: (a) language users must be aware of intrinsic object properties and evaluate them and (b) they should know about its consequences for verb use. Arguably, for French and English L2 users of Dutch, processing leggen would be more costly than processing zetten when looking at the visual display, as it requires an assessment of inherent object properties above and beyond the configurational relation between the object and the surface (its position relative to the table/chair). Although Fig. 7 suggests that the French/ English L2 participants have more difficulty integrating the object noun after hearing leggen than after hearing zetten, we did not find a significant difference between zetten and leggen in affecting the probability of fixating the target object over the position distracter in any of the time windows (LME models, all p's > .3). Tentative patterns emerging from the additional experiment on this population (see discussion of experiment 3 ) do suggest that L objects represent a special case: French/English L2 participants may have greater difficulty assigning the correct placement verb to these items. In this respect, results of the present study cannot be directly linked to production studies on placement verbs, as these have not investigated inherent object properties, i.e., differences between SL and L-only objects. Production research has reported more overextensions of leggen (or legen in German) than of zetten in both L1 and L2 acquisition (Alferink \& Gullberg, 2014; Berthele, 2012; Narasimhan \& Gullberg, 2011), which suggests a more default reliance on leggen over zetten. This could potentially be related to differences between object types: leggen/liggen can in principle be used to describe all object types, whereas the use of zetten/ staan is restricted to SL objects. This would qualify leggen as a more suitable candidate for overgeneralization in production specifically. Of course, this hypothesis warrants further research, as our findings on potential differences between SL and $\mathrm{L}$ objects in L2 processing centers on a small data set from an additional experiment, and it is not the main focus of the present study. Future research could investigate the role of linguistic (verbal) versus object knowledge during L1 and L2 processing more systematically, for instance by comparing participants with different proficiency levels (beit general L2 proficiency or placement verb-specific proficiency): we would expect any inherent processing differences between zetten and leggen to decrease as experience with the semantic representations of the verbs increases. Moreover, if the semantic representation of leggen in comprehension is indeed more complex than the representation of zetten, we expect to find prediction effects for zetten earlier than for leggen (if at all).

\footnotetext{
18 The distinction between Korean tight and loose fit verbs has also been shown to depend on inherent object properties (Chang, Choi, \& Ko, 2015).
} 
Another question is how much exposure to a linguistic feature is needed to be able to use it predictively. If a specific linguistic feature is absent in one's native language, is it possible to generate predictions on the basis of that feature in an L2 at all? Research by Hopp (2013) suggests that it is: he found that English L2 users of German indeed anticipated objects on the basis of a morphosyntactic cue that does not exist in their L1 (grammatical gender), but this was limited to those L2 users who consistently assigned the correct gender in L2 production. He claims that a strong enough lexical representation (in his case, of gender) is a prerequisite for prediction in L2 processing. With respect to the present study, the lack of anticipatory behavior in our sample of French/English L2 Dutch participants would suggest that their semantic representation of placement verbs is not strong enough. Yet, we did find a significant verb effect on fixations on standing vs. lying targets in the integration time window (albeit late), which suggests that participants integrated the positional information in their representation of the placement event and hence had mastered the semantic distinction between zetten and leggen. Unfortunately, we cannot provide the reader with data to assess the strength of this semantic representation in the specific French/English L2 sample tested in the eye tracking experiment. Hence, we cannot exclude the possibility that L2 users with more experience and more consistent representations of placement verb semantics would be able to use these cues predictively, regardless of their native language background. Importantly, the additional production and comprehension accuracy data underline our interpretation of the lack of prediction as related to native language experience and the processing automaticity associated with it, and suggests that knowing the meaning of a verb is not the sole prerequisite for being able to use it predictively.

There may also be a difference in the ease with which language-specific semantic vs. language-specific morphosyntactic information is used for prediction in L2 processing, as also suggested by Hopp (2015). Hopp (2015) considers predictive use of morphosyntactic information to be more challenging than predictive use of semantic information, but as already noted before, he thereby disregards the variation in L1-L2 overlap concerning these types of information. It is not unthinkable that building up new conceptual-semantic representations is more difficult than creating lexical representations. In the field of cross-linguistic influence in language learning (discussed in e.g., Gullberg, 2009), it is assumed that most L2 difficulties arise when an existing L1 category has to be split up into two L2 categories, because it "involves the need to shift semantic boundaries of existing categories in the L1 and re-structure semantic-conceptual representations" (Gullberg, 2009, p. 223). L2 production studies on placement events show that fully mastering two specific semantic categories of placement in an L2 is indeed highly challenging (e.g., Alferink \& Gullberg, 2014; Berthele, 2012; Gullberg, 2009). Perhaps such conceptual-semantic representations will never be strong enough for predictive use in L2 processing, unlike morphosyntactic representations (such as gender; cf. Hopp, 2015). On the basis of our current findings it is not possible to give a conclusive answer; future research could investigate this by directly comparing use of morphosyntactic and conceptualsemantic features in predictive L2 processing which are both absent in the L1 of the same L2 sample.

\section{Conclusions}

Using a cross-linguistic comparison of L2 processing has proven to be a valuable tool to shed light on general mechanisms of prediction in language processing. Our findings add to the evidence that linguistic experience modulates predictive sentence processing (in line with Mishra et al., 2012; Wells et al., 2009). In this specific case, experience concerned prior exposure to language-specific verbal semantics through the native language. This is the first time that cross-linguistic diversity in verbal semantics has been a topic for investigation of experience in prediction, thus extending key findings on verbal predictive cues (e.g., in Altmann \& Kamide, 1999). Our findings underline that prediction is a key part of language comprehension, and add to the evidence that individual factors (in our case, linguistic experience) mediate this process.

\section{Acknowledgments}

We gratefully acknowledge the Netherlands Organization for Scientific Research (NWO) for financial support of this project [Veni grants 275-89-022 to the first author and 275-89-011 to the second author]. We would like to thank Anne Pier Salverda for feedback on the statistical analyses, as well as Florian Jaeger, Sander Lestrade and Kirsten Weber for helpful comments on earlier drafts; we also owe gratitude to the audiences of AMLaP 2014 and CUNY 2015, at which we presented preliminary versions of this paper. Thanks also go to Ceci Verbaarschot and Sander Lestrade for their help with data preprocessing, and to Lonneke Oudshoorn, Sarah Smirnow, Jakob Lesage, Laura de Weger and Aukje van Pelt for help with stimulus design and data collection. 


\section{Appendix A. Names and types of objects}

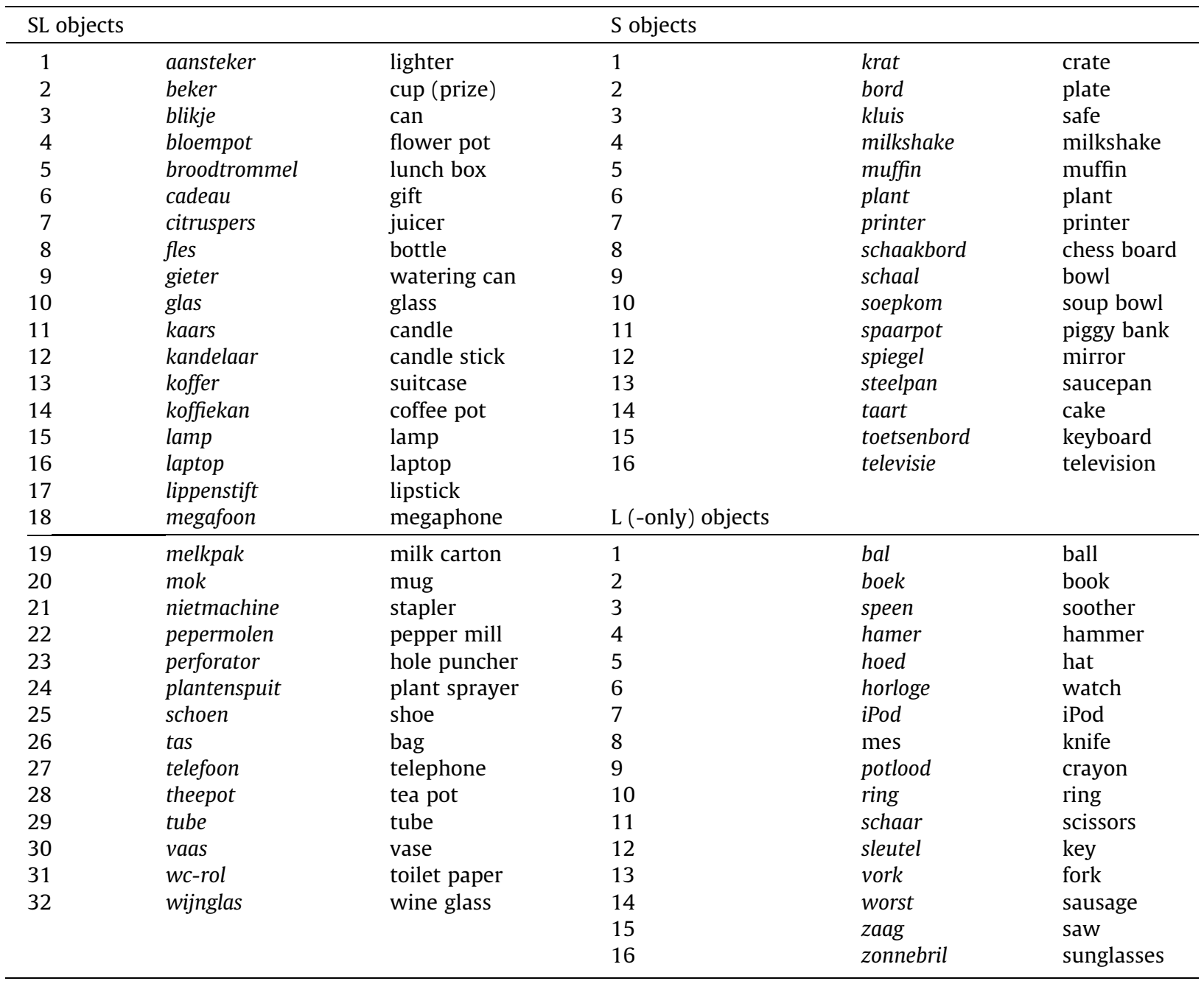

\section{Appendix B. Supplementary material}

Supplementary data associated with this article can be found, in the online version, at http://dx.doi.org/10.1016/ j.jml.2016.05.003.

\section{References}

Alferink, I., \& Gullberg, M. (2014). French-Dutch bilinguals do not maintain obligatory semantic distinctions: Evidence from placement verbs. Bilingualism: Language and Cognition, 17, 22-37.

Altmann, G. T., \& Kamide, Y. (1999). Incremental interpretation at verbs: Restricting the domain of subsequent reference. Cognition, 73, 247-264.

Berthele, R. (2012). On the use of PUT verbs by multilingual speakers of Romansh. In A. Kopecka \& B. Narasimhan (Eds.), Events of putting and taking: A crosslinguistic perspective (pp. 145-166). Amsterdam: John Benjamins.

Boersma, P., \& Weenink, D. (2015). Praat: Doing phonetics by computer [Computer program]. Version 5.4.15. <http://www.praat.org/> Retrieved January 2015.

Huettig, F., \& Brouwer, S. (2015). Delayed anticipatory spoken language processing in adults with dyslexia: Evidence from eye-tracking. Dyslexia, 21, 97-122.
Cadierno, T., Ibarretxe-Antuñano, I., \& Hijazo-Gascón, A. (2016). Semantic categorization of placement verbs in L1 and L2 Danish and Spanish. Language Learning, 66, 191-223.

CGN (Corpus Gesproken Nederlands) (2004). Distributed by the Dutch language union. <http://lands.let.ru.nl/cgn/home.htm>.

Chang, F., Baumann, M., Pappert, S., \& Fitz, H. (2014). Do lemmas speak German? A verb position effect in German structural priming. Cognitive Science, 1-18.

Chang, F., Choi, Y., \& Ko, Y. (2015). Why loose rings can be tight: The role of learned object knowledge in the development of Korean spatial fit terms. Cognition, 136, 196-203.

Chang, F., Dell, G., \& Bock, K. (2006). Becoming syntactic. Psychological Review, 113, 234-272.

Clark, A. (2013). Whatever next? Predictive brains, situated agents, and the future of cognitive science. Behavioral and Brain Sciences, 36, $181-204$.

Council of Europe (2001). Common European Framework of Reference for languages: Learning, teaching and assessment.Cambridge: Cambridge University Press.

Dahan, D., \& Tanenhaus, M. (2000). Continuous mapping from sound to meaning in spoken language comprehension: Immediate effects of verb-based thematic constraints. Journal of Experimental Psychology: Learning, Memory, and Cognition, 30, 498-513.

DeLong, K., Urbach, T., \& Kutas, M. (2005). Probabilistic word preactivation during language comprehension inferred from electrical brain activity. Nature Neuroscience, 8, 1117-1121. 
Dussias, P., Valdes Kroff, J., Guzzardo Tamargo, R., \& Gerfen, C. (2013). When gender and looking go hand in hand: Grammatical gender processing in L2 Spanish. Studies in Second Language Acquisition, 35, $353-387$.

Farmer, T., Brown, M., \& Tanenhaus, M. (2013). Prediction, explanation, and the role of generative models in language processing. Behavioral and Brain Sciences, 36, 211-212.

Farmer, T., Fine, A., \& Jaeger, T. (2011). Implicit context-specific learning leads to rapid shifts in syntactic expectations. In L. Carlson, C. Holscher, \& T. Shipley (Eds.), Proceedings of the 33rd annual conference of the cognitive science society (pp. 2055-2060). Austin: Cognitive Science Society.

Federmeier, K. (2007). Thinking ahead: The role and roots of prediction in language comprehension. Psychophysiology, 44, 491-505.

Federmeier, K., \& Kutas, M. (1999). A rose by any other name: Long-term memory structure and sentence processing. Journal of Memory and Language, 41, 469-495.

Fine, A., Jaeger, T. F., Farmer, T., \& Qian, T. (2013). Rapid expectation adaptation during syntactic comprehension. PLoS One, 8, e77661.

Flecken, M., Carroll, M., Weimar, K., \& Von Stutterheim, C. (2015). Driving along the road or heading for the village? Conceptual differences underlying motion event encoding in French, German, and FrenchGerman L2 users. Modern Language Journal, 99, 100-122.

Flecken, M., Gerwien, J., Carroll, M., \& von Stutterheim, C. (2015). Analyzing gaze allocation during language planning: A crosslinguistic study on dynamic events. Language and Cognition, 7, $138-166$.

Foucart, A., Martin, C., Moreno, E., \& Costa, A. (2014). Can bilinguals see it coming? Word anticipation in L2 sentence reading. Journal of Experimental Psychology: Learning, Memory, and Cognition, 40, 1461-1469.

Gullberg, M. (2009). Reconstructing verb meaning in a second language. How English speakers of L2 Dutch talk and gesture about placement. Annual Review of Cognitive Linguistics, 7, 221-224.

Gullberg, M. (2011). Language-specific encoding of placement events in gestures. In E. Pederson \& J. Bohnemeyer (Eds.), Event representation in language and cognition (pp. 166-188). Cambridge: CUP.

Hahne, A. (2001). What's different in second language processing? Evidence from event-related brain potentials. Journal of Psycholinguistic Research, 30, 251-266.

Hale, J. (2003). The information conveyed by words in sentences. Journal of Psycholinguistic Research, 32, 101-123.

Hare, M., Jones, M., Thomson, C., Kelly, S., \& McRae, K. (2009). Activating event knowledge. Cognition, 111, 151-167.

Hopp, H. (2010). Ultimate attainment in L2 inflection: Performance similarities between non-native and native speakers. Lingua, 120, 901-931.

Hopp, H. (2013). Grammatical gender in adult L2 acquisition: Relations between lexical and syntactic variability. Second Language Research, 29, 33-56.

Hopp, H. (2015). Individual differences in the second language processing of object-subject ambiguities. Applied Psycholinguistics, 36, 129-173.

Huettig, F. (2015). Four central questions about prediction in language processing. Brain Research, 1626, 118-135.

Huettig, F., \& Janse, E. (2016). Individual differences in working memory and processing speed predict anticipatory spoken language processing in the visual world. Language, Cognition and Neuroscience, 31, 80-93.

Huettig, F., Meyer, A., \& Rommers, J. (2011). Using the visual world paradigm to study language processing: A review and critical evaluation. Acta Psychologica, 137, 151-171.

Jaeger, T. F., \& Norcliffe, E. (2009). The cross-linguistic study of sentence production: State of the art and a call for action. Language and Linguistics Compass, 3, 866-887.

Jaeger, T. F., \& Snider, N. E. (2013). Alignment as a consequence of expectation adaption: Syntactic priming is affected by the prime's prediction error given both prior and recent experience. Cognition, 127, 57-83.

Jarvis, S., \& Pavlenko, A. (Eds.). (2008). Crosslinguistic influence in language and cognition. London: Routledge.

Kaan, E. (2014). Predictive sentence processing in L2 and L1: What is different? Linguistic Approaches to Bilingualism, 4, 257-282.

Kaiser, E., \& Trueswell, J. C. (2004). The role of discourse context in the processing of a flexible word-order language. Cognition, 94, 113-147.

Kamide, Y. (2008). Anticipatory processes in sentence processing. Language and Linguistics Compass, 2, 647-670.

Kamide, Y., Altmann, G., \& Haywood, S. (2003). The time-course of prediction in incremental sentence processing: Evidence from anticipatory eye movements. Journal of Memory and Language, 49, $133-156$.
Kamide, Y., Scheepers, C., \& Altmann, G. (2003). Integration of syntactic and semantic information in predictive processing: Cross-linguistic evidence from German and English. Journal of Psycholinguistic Research, 32, 37-55.

Knoeferle, P., Crocker, M., Scheepers, C., \& Pickering, M. (2005). The influence of the immediate visual context on incremental thematic role-assignment: Evidence from eye-movements in depicted events. Cognition, 95, 95-127.

Koehne, J., \& Crocker, M. (2015). The interplay of cross-situational word learning and sentence-level constraints. Cognitive Science, 39, 849-889.

Kopecka, A., \& Narasimhan, B. (2012). Events of putting and taking: A crosslinguistic perspective.Amsterdam: John Benjamins.

Kuperberg, G., \& Jaeger, T. F. (2016). What do we mean by prediction in language comprehension? Language, Cognition and Neuroscience, 31, 32-59.

Kuperman, V., \& van Dyke, J. (2011). Effects of individual differences in verbal skills on eye-movement patterns during sentence reading. Journal of Memory and Language, 65, 45-73.

Kurumada, C., Brown, M., Bibyk, S., Pontillo, D., \& Tanenhaus, M. (2014). Is it or isn't it: Listeners make rapid use of prosody to infer speaker meanings. Cognition, 122, 335-342.

Kutas, M., Delong, K., \& Smith, N. (2011). A look around at what lies ahead: Prediction and predictability in language processing. In M. Bar (Ed.), Predictions in the brain: Using our past to generate a future (pp. 190-207). Oxford: Oxford University Press.

Lemhöfer, K., \& Broersma, M. (2012). Introducing LexTALE: A quick and valid lexical test for advanced learners of English. Behavior Research Methods, 44, 325-343.

Lemmens, M. (2006). Caused posture: Experiential patterns emerging from corpus research. In S. Gries \& A. Stefanowitsch (Eds.), Corpora in cognitive linguistics. The syntax-lexis interface (Vol. II, pp. 261-296). Berlin: Mouton de Gruyter.

Lemmens, M. (2002). The semantic network of Dutch posture verbs. In J. Newman (Ed.), The linguistics of sitting, standing and lying (pp. 103-139). Amsterdam: John Benjamins.

Levy, R. (2008). Expectation-based syntactic comprehension. Cognition, $106,1126-1177$.

MacDonald, M. (1994). Probabilistic constraints and syntactic ambiguity resolution. Language and Cognitive Processes, 9, 157-201.

MacDonald, M. (2013). How language production shapes language form and comprehension. Frontiers in Psychology, 4. http://dx.doi.org/ 10.3389/fpsyg.2013.00226.

Mani, N., \& Huettig, F. (2012). Prediction during language processing is a piece of cake - But only for skilled producers. Journal of Experimental Psychology: Human Perception and Performance, 38, 843-847.

Mani, N., \& Huettig, F. (2014). Word reading skill predicts anticipation of upcoming spoken language input: A study of children developing proficiency in reading. Journal of Experimental Child Psychology, 126, 264-279.

Martin, C., Thierry, G., Kuipers, J., Boutonnet, B., Foucart, A., \& Costa, A. (2013). Bilinguals reading in their second language do not predict upcoming words as native readers do. Journal of Memory and Language, 69, 574-588.

McRae, K., \& Matsuki, K. (2013). Constraint-based models of sentence processing. In R. Van Gompel (Ed.), Sentence processing (pp. 51-77). New York: Psychology Press.

Mishra, R., Singh, N., Pandey, A., \& Huettig, F. (2012). Spoken languagemediated anticipatory eye movements are modulated by reading ability: Evidence from Indian low and high literates. Journal of Eye Movement Research, 5, 1-10.

Narasimhan, B., \& Gullberg, M. (2011). The role of input frequency and semantic transparency in the acquisition of verb meaning: Evidence from placement verbs in Tamil and Dutch. Journal of Child Language, $38,504-532$

Odlin, T. (1989). Language transfer: Cross-linguistic influence in language learning.Cambridge: Cambridge University Press.

Odlin, T. (2005). Crosslinguistic influence and conceptual transfer: What are the concepts? Annual Review of Applied Linguistics, 25, 3-25.

Pavlenko, A. (2011). Thinking and speaking in two languages. Clevedon, UK: Multilingual Matters.

Pickering, M., \& Garrod, S. (2013). An integrated theory of language production and comprehension. Behavioral and Brain Sciences, 36, 329-347.

Rommers, J., Meyer, A., Praamstra, P., \& Huettig, F. (2013). The contents of predictions in sentence comprehension: Activation of the shape of objects before they are referred to. Neuropsychologia, 51, 437-447.

Salverda, A. P., Kleinschmidt, D., \& Tanenhaus, M. K. (2014). Immediate effects of anticipatory coarticulation in spoken-word recognition. Journal of Memory and Language, 71(1), 145-163. 
Slobin, D. (1996). From "thought and language" to "thinking for speaking”. In J. J. Gumperz \& S. Levinson (Eds.), Rethinking linguistic relativity (pp. 70-96). Cambridge: Cambridge University Press.

Talmy, L. (2000). Toward a cognitive semantics. Typology and process in concept structuring (Vol. II)Cambridge: MIT Press.

Tanenhaus, M., Spivey-Knowlton, M., Eberhard, K., \& Sedivy, J. (1995). Integration of visual and linguistic information during spoken language comprehension. Science, 268, 1632-1634.

Trenkic, D., Mirkovic, J., \& Altmann, G. (2014). Real-time grammar processing by native and non-native speakers: Constructions unique to the second language. Bilingualism: Language and Cognition, 17, 237-257.

van Berkum, J. (2010). The brain is a prediction machine that cares about good and bad - Any implications for neuropragmatics? Italian Journal of Linguistics, 22, 181-208. van Berkum, J., Brown, C., Zwitserlood, P., Kooijman, V., \& Hagoort, P. (2005). Anticipating upcoming words in discourse: Evidence from ERPs and reading times. Journal of Experimental Psychology: Learning, Memory, and Cognition, 31, 443-467.

van Petten, C., \& Luka, B. (2012). Prediction during language comprehension: Benefits, costs and ERP components. Journal of Psychophysiology, 83, 176-190.

Weber-Fox, C., \& Neville, H. (1996). Maturational constraints on functional specializations for language processing: ERP and behavioral evidence in bilingual speakers. Journal of Cognitive Neuroscience, 8, 231-256.

Wells, J., Christiansen, M., Race, D., Acheson, D., \& MacDonald, M. (2009). Experience and sentence processing: Statistical learning and relative clause comprehension. Cognitive Psychology, 58, 250-271. 